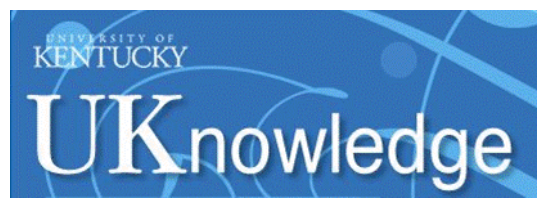

University of Kentucky

UKnowledge

\title{
Intake and Growth of Steers Offered Different Allowances of Autumn Grass and Concentrates
}

\section{Edward G. O'Riordan}

Teagasc, Ireland

P. French

Teagasc, Ireland

Padraig O’Kiely

Teagasc, Ireland
A. P. Moloney
Teagasc, Ireland

Follow this and additional works at: https://uknowledge.uky.edu/igc

Part of the Plant Sciences Commons, and the Soil Science Commons

This document is available at https://uknowledge.uky.edu/igc/19/19/16

The XIX International Grassland Congress took place in São Pedro, São Paulo, Brazil from February 11 through February 21, 2001.

Proceedings published by Fundacao de Estudos Agrarios Luiz de Queiroz

This Event is brought to you for free and open access by the Plant and Soil Sciences at UKnowledge. It has been accepted for inclusion in International Grassland Congress Proceedings by an authorized administrator of UKnowledge. For more information, please contact UKnowledge@lsv.uky.edu. 
ID \# 19-16

\title{
INTAKE AND GROWTH OF STEERS OFFERED DIFFERENT ALLOWANCES OF AUTUMN GRASS AND CONCENTRATES.
}

\author{
E.G. O’Riordan, P. French, P. O' Kiely and A.P. Moloney
}

Teagasc, Grange Research Centre, Dunsany, Co. Meath, Ireland.

\begin{abstract}
The aim of this experiment was to quantify the relationship between autumn grass supply and concentrate supplementation level on grass intake and animal performance. One hundred and ten continental steers $(567 \mathrm{~kg})$ were assigned to ten treatments in a three grass allowances: $(6,12$ and $18 \mathrm{~kg}$ dry matter (DM) per head daily) by three concentrate levels: $(0,2.5$ and $5 \mathrm{~kg} / \mathrm{head} /$ daily) factorial design with a positive control group offered concentrates ad-libitum. Grass allowance was offered daily and concentrates were fed individually. The experiment began on August 22 and all animals were slaughtered after a mean experimental period of 95 days. Grass allowance increased $(\mathrm{P}<0.001)$ complete diet digestibility only in the absence of concentrates and supplementary concentrates increased $(\mathrm{P}<0.001)$ complete diet digestibility only at the low grass allowance. Both offering animals supplementary concentrates $(\mathrm{P}<0.001)$ and increasing daily grass allowance $(\mathrm{P}<0.001)$ increased their carcass growth rate. Grazed grass supported only one third the carcass growth rate of supplementary concentrates per $\mathrm{kg}$ of DM eaten. As a strategy for
\end{abstract}


increasing the performance of cattle grazing autumn grass, offering supplementary concentrates offers more scope than altering grass allowance.

Keywords: Autumn grass allowance, concentrates, steers

\section{Introduction}

Two strategies that could potentially increase performance of cattle grazing autumn grass (lolium perenne) are an increase in the supply of grass or offering additional feedstuffs such as supplementary concentrates. Previous research in which supplementary concentrates were offered to cattle grazing grass has shown that where pasture supply was adequate, there was no significant animal production response to concentrates (Steen, 1994 and Steen and Kilpatrick, 1998). Conway (1968) hypothesised that when offered supplementary concentrates with adequate grass, cattle substituted part of their dietary grass intake for concentrates while maintaining performance. These published trials evaluated supplementation in either the early part of the grazing season when grass quality is generally good, or throughout the entire grazing season, thereby not evaluating the potential advantage of supplementation in autumn when pasture supply or quality may be limiting.

An alternative strategy to concentrate supplementation for maintaining animal performance is to increase the allowance of grazed grass. Reed (1978) postulated that offering an increased allowance of grass during the autumn period would enable animals to impose a greater degree of selection on the grass consumed, maximise grass intake and thus minimise the seasonal depression in animal performance.

The objective of this experiment was to quantify the response to grass supply and level of concentrate supplementation on grass intake and steer performance in the autumn. 


\section{Material and Methods}

One hundred and ten continental cross steers (mean liveweight 567kg) were blocked on weight and breed and assigned to ten treatments in a three (herbage allowances) by three (concentrate levels) factorial design plus a positive control. Initial liveweights were based on weights recorded on two consecutive days. Herbage allowances of 6, 12 and $18 \mathrm{~kg} \mathrm{DM} / \mathrm{hd}$ were offered daily which approximated to 0.01 , 0.02 , and 0.03 of bodyweight. Concentrate allowances of $0,2.5$ and $5 \mathrm{~kg}$ fresh weight were offered to animals individually and twice daily to those receiving $5 \mathrm{~kg} /$ day $(2 \mathrm{X} 2.5 \mathrm{~kg})$. The positive control treatment, which did not have access to grass, was offered the same concentrates ad-libitum in an outdoor environment. The concentrate used contained barley (0.29), unmolassed beet pulp (0.29) maize gluten (0.29) soya bean $(0.05)$ molasses $(0.05)$ and min/vit.(0.03). Pre-grazing herbage yields were determined three times per week by cutting six strips $(1.2 \mathrm{~m} \times 5 \mathrm{~m})$ from the swards about to be grazed. Based on the pregrazing yields, treatment groups were offered a precise area to ensure the appropriate herbage allowance. Animals were offered the fresh herbage daily after being given the morning concentrate supplement. Post- grazing yield was estimated 3 times per week and grass intake was estimated for each treatment based on the difference between the preand post- grazing yields. Individual animal intake and complete diet digestibility was measured using the n-Alkanes C32 and C36. The experiment covered the period from August 22 to December 1. 


\section{Results and Discussion}

Increasing the daily grass allowance increased grass intake and at the unsupplemented high grass (18 $\mathrm{kgDM} / \mathrm{head} /$ day), allowance equivalent to $30 \mathrm{~g} \mathrm{DM} / \mathrm{kg}$ bodyweight animals achieved 0.97 of the DM intake of the positive control offered concentrates ad-libitium. Offering $4.4 \mathrm{kgDM}$ concentrate at this grass allowance increased total DM intake by only $0.81 \mathrm{~kg}$ DM. At the low grass allowance, grass intakes were approximately $5.5 \mathrm{kgDM}$ and there was no effect of offering animals supplementary concentrates on their grass intake. At the medium and high grass allowances, supplementary concentrates reduced grass intake by 0.43 and $0.81 \mathrm{kgDM}$ respectively per $\mathrm{kgDM}$ concentrate offered.

Offering animals supplementary concentrates at the medium and high grass allowance increased their complete diet OM digestibility even though offering supplementary concentrates also increased total $\mathrm{OM}$ intake. At the low grass allowance there was no effect of concentrate supplementation on grass intake so therefore an evaluation of the effect of concentrate supplementation on grass digestibility can be made. When these animals were offered $2.5 \mathrm{~kg}$ concentrate, their complete diet OM digestibility was higher than the additive values of the grass (estimated from the unsupplemented animals) and concentrates (estimated in-vitro) even though total DM intake was significantly increased. This would imply that the supplementary concentrates increased the grass DM digestibility.

Relative to the animals offered the low grass allowance and no concentrate, supplementing with concentrate increased carcass growth by $116 \mathrm{~g} / \mathrm{kg}$ concentrate DM eaten whereas increasing the grass allowance, increased carcass growth by $38 \mathrm{~g} / \mathrm{kg} \mathrm{DM}$ grass eaten. The carcass weight response to concentrates of these groups of grazing animals was twice that of the treatment offered concentrates ad-libitum which gained $57 \mathrm{~g}$ 
carcass per $\mathrm{kg}$ concentrate DM eaten. This data supports our previous assumption that there was more than an additive effect by supplementing autumn grass with concentrates on diet digestibility.

Although there was a much larger (double) carcass growth response to supplementary concentrates than to additional grass DM eaten, increasing grass intake significantly increased carcass fat scores whereas offering supplementary concentrates did not. This would imply that relative to concentrates, increasing allowance of autumn grass led to a change in partitioning of energy, from muscle, towards subcutaneous fat.

Per kg of DM eaten, grass supported only one third the carcass growth of supplementary concentrates. In conclusion, as a strategy for increasing the performance of cattle grazing the type of autumn grass used in this study, offering supplementary concentrates offers more scope than altering grass allowance.

\section{References}

Conway, A. (1968). Grazing management in relation to beef production. V. Effect of feeding supplements to beef cattle on pasture at two intensities of stocking. Irish Journal of Agricultural Research 7: 105-120.

Reed, K.F.M. (1978). The effect of season of growth on the feeding value of pasture. Journal British Grassland Society 33: 227-234

Steen, R.W.J. (1994). A comparison of pasture grazing and storage feeding, and the effects of sward surface height and concentrate supplementation from 5 to 10 months of age on the lifetime performance and carcass composition of bulls. Animal Production, 58: 209-219

Steen, R.W.J. and Kilpatrick D.J. (1998). Effects of pasture grazing and storage feeding and concentrate input between 5.5 and 11 months of age on the performance and carcass 
composition of bulls and on subsequent growth and carcass composition at $620 \mathrm{~kg}$ live weight. Animal Science, 66: 129-141. 
Table 1 - The effect of grass allowance and concentrate level (kg/head/day) on intake, diet digestibility, feed efficiency, animal growth, and carcass and plasma characteristics

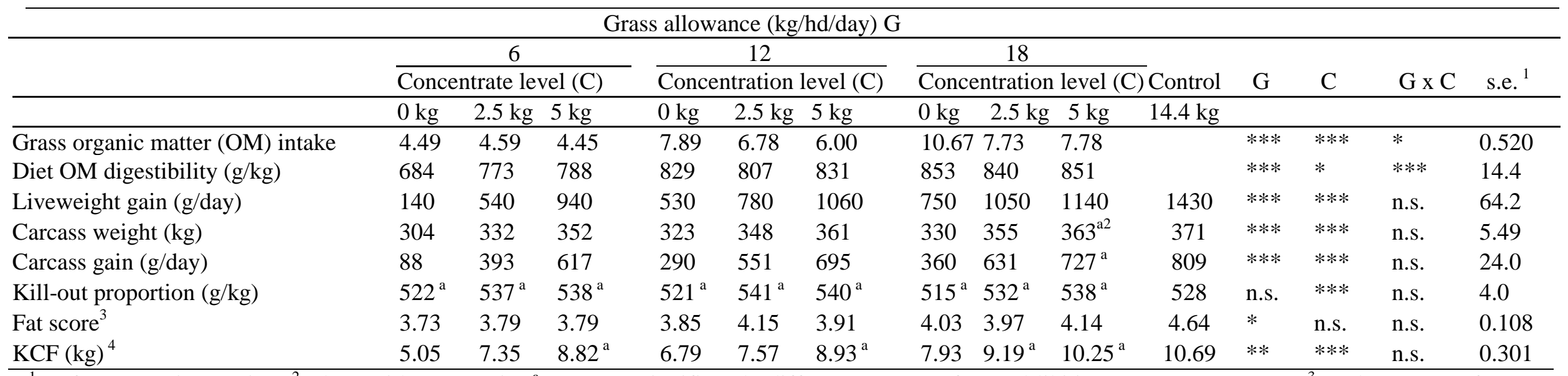

${ }^{1}$ s.e for $\mathrm{G} \times \mathrm{C}$ interaction, ${ }^{2}$ values with superscript ${ }^{\mathrm{a}}$ were not significantly different $(\mathrm{P}<0.05)$ from ad-libitium concentrate group, ${ }^{3} 1=$ leanest $5=$ fattest; ${ }^{4}$ kidney plus channel fat, 